\title{
Effect of bio-based phytate (PA-THAM) on the flame retardant and mechanical properties of polylactide (PLA)
}

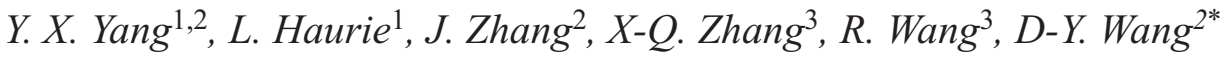 \\ ${ }^{1}$ Department of Tecnologia de l'Arquitectura, Universitat Politècnica de Catalunya, Av. Dr. Marañon 44-50, 08028 \\ Barcelona, Spain \\ ${ }^{2}$ IMDEA Materials Institute, C/Eric Kandel, 2, 28906 Getafe, Madrid, Spain \\ ${ }^{3}$ School of Materials Science and Technology, Beijing Institute of Fashion Technology, Beijing, China
}

Received 25 September 2019; accepted in revised form 21 December 2019

\begin{abstract}
A novel bio-based flame retardant (Phytic acid - trometamol, PA-THAM) was prepared via salt formation reaction between phytic acid and trometamol. The chemical structure and thermal stability of this novel phytate were characterized by Nuclear magnetic resonance spectroscopy (NMR), Fourier transform infrared spectroscopy (FTIR), and Thermogravimetric analysis (TGA). Afterward, the effect of PA-THAM on the flammability of PLA was investigated. On the basis of the results, $3 \mathrm{wt} \%$ incorporation of PA-THAM in PLA exhibited better results than pure PLA in flame combustion tests, for example, LOI value increased from 19.9 to $25.8 \%$ and ratings in UL-94 varied from No Rating to V-0 rating. This ignitionresistance performance was analyzed investigating the relationship between properties and structure. The results elucidated that the incorporation of PA-THAM significantly reduced the molten viscosity of biocomposite, which facilitated the 'heat transfer' effect to rapidly decrease the surface temperature. In comparison with neat PLA, the same load of PA-THAM in PLA had little effect on the mechanical properties of PLA-based biocomposite, which indicated that the optimum load of PA-THAM maintained the balance of fire retardancy and mechanical properties of the PLA biocomposite.
\end{abstract}

Keywords: biocomposites, polylactide, bio-based flame retardant

\section{Introduction}

Recently, issues of environmental pollution and energy depletion induce more and more researchers to focus on the study of new generation materials. Therefore, the eco-friendly and biodegradable materials demonstrate significant potential to be increasing substitutes for the traditional petrochemical-based materials. Among these alternatives, polylactide (PLA) is the most popular investigated aliphatic polyester for the application in architecture [1], package [2], engineering [3], and medical fields [4], due to its comprehensive performance, such as bioresource, biocompatibility, non-toxic degradation products, and mechanical properties $[5,6]$. Despite these advantages, the inherent flammability still limits
PLA further application, which was already studied by some groups $[7,8]$.

In order to enhance flame retardant properties of PLA, some aspects related to the fire behaviors could be considered, such as delaying ignition time, increasing the ignition temperature, raising the limiting oxygen index, or decreasing the heat release and toxic products during combustion. Considering that halogenated flame retardants result in environmental problems, more and more halogen-free alternatives had been developed. Zhao et al. [9] prepared a flame-retarded PLA by adding a phosphorus-containing flame retardant, shown good LOI value as well as achieved UL-94 V-0 rating. Xia et al. [10] reported a multi-hydroxy-containing phosphate (DPPT) 
and incorporated it into PLA; due to the fire-inhibition activity of DPPT, PLA composite reached an LOI value of $32.7 \%$ and passed UL-94 V-0 rating. Moreover, another functionalized phosphorus-containing flame retardant(HNT@MAH@DOPO)was fabricated by our group [11], which imparted PLA composite a higher initial thermo-oxidation stability and excellent flame retardant performance $(\mathrm{LOI}=$ $38.0 \%$ and UL-94 V-0).

Besides, some bio-based flame retardants are already reported in previous investigations [12, 13], and these additives played a flame retardant role on the matrix generally due to the existence of some active elements, such as phosphorus or nitrogen. A new biobased flame retardant (LHP) was synthesized and applied to PLA [14]. The combination of LHP and ammonium polyphosphate (APP) at 1:3 ratio imparted PLA composite a significant reduction in PHRR by $31.5 \%$. Jiang et al. [15] modified natural sepiolite (SEP) with phosphaphenanthrene derivative (DOPO) and the $10 \mathrm{wt} \%$ incorporation of SEP-DOPO into PLA exhibited increased flame retardancy and thermal stability due to the synergistic effect between SEP and DOPO. A hybrid flame retardant system BSDH was combined with APP to increase the flame retardant properties of PLA [16], and the addition of $10 \mathrm{wt} \%$ mixed additives in PLA demonstrated $49 \%$ lower value in PHRR than pure PLA did.

As these reports above show, phosphorus-containing compounds impart high-efficiency flame retardant properties on PLA biocomposite. Therefore, this work was aiming to develop a novel phosphorus-containing flame retardant on the basis of the bio-based concept. Phytic acid, as a bio-based substance extracted from plant seeds, bran, legumes, and grains, can be employed as a flame retardant for fire safety materials due to its high phosphorus and oxygen content, and there are some achievements in fire resistance application of phytic acid. Zhou et al. [17] prepared a polyaniline-deposited paper composite by using phytic acid as dopant or co-dopant to enhance the flame retardancy; moreover, Costes et al. [18] developed a PLA-based composite system by combining lignin and phytic acid to improve both fire resistance and dispersion of lignin in the matrix.

However, phytic acid, conserved as liquid form, was rarely reported to add into PLA directly, which would present some adverse problems during the melt-mixing process. Therefore, the addition of phytate is considered as an effective way to improve the processing conditions. In this study, trometamol, which is used as a buffer in the application of biochemistry and molecular biology, was selected to react with phytic acid via salt formation owing to the presence of a primary amine. Afterward, this novel bio-based phytate PA-THAM was incorporated into PLA, and the thermal stability, flame retardant performance, as well as mechanical properties, were investigated systematically.

\section{Materials and methods}

\subsection{Materials}

Polylactide (PLA, 4043D), a multi-purpose extrusion grade, was purchased from NatureWorks (Minnetonka, MN, USA). Phytic acid (PA, $50 \mathrm{wt} \%$ ) and trometamol (THAM) were obtained from SigmaAldrich Corporation and used without further purification.

\subsection{Synthesis of flame retardant (PA-THAM)}

The synthesis route of PA-THAM was depicted in Figure 1. THAM (60 mmol) was dissolved in ethanol in a three-neck flask with a condenser pipe at $70^{\circ} \mathrm{C}$. Then, PA ( $5 \mathrm{mmol})$ was dropped slowly into the flask with stirring until the reaction completed. The mixture was cooled down to room temperature, and the collected white precipitate was washed with ethanol to remove the residue. Finally, light yellow PATHAM with $80 \%$ yield was obtained after drying in a vacuum oven at $150^{\circ} \mathrm{C}$ for $2 \mathrm{~h}$.

\subsection{Preparation of PLA and its biocomposites}

The formulations of PLA biocomposites (listed in Table 1) were fabricated in a micro-compounder (MC 15, Xplore) at $170^{\circ} \mathrm{C}$ for $2 \mathrm{~min}$. The reference sample (pristine PLA) was also prepared under the same conditions. Test samples were molded according to the relevant standards by a hot-press (LabPro 400 , Fontijne Presses) at $170^{\circ} \mathrm{C}$ for $5 \mathrm{~min}$. All the materials were dried in a vacuum oven at $80^{\circ} \mathrm{C}$ for at least $8 \mathrm{~h}$ before processing.

\subsection{Characterization}

${ }^{1} \mathrm{H}$ NMR, ${ }^{13} \mathrm{C}$ NMR, and ${ }^{31} \mathrm{P}$ NMR spectra, FTIR, and TGA techniques were used to characterize the structure and thermal property of flame-retardant PATHAM. A Varian Infinity AS400 (B0=9.4T) (Bruker Co., Germany) was used for the NMR test in $\mathrm{D}_{2} \mathrm{O}$ solvent at room temperature. Chemical shifts $(\delta)$ were reported in ppm, while spectra were referenced by 
<smiles>O=P(O)(O)OC1C(OP(=O)(O)O)[C@H](OP(=O)(O)O)C(OP(=O)(O)O)[C@@H](OP(=O)(O)O)C1OP(=O)(O)O</smiles>

PA

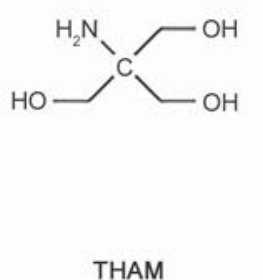

THAM

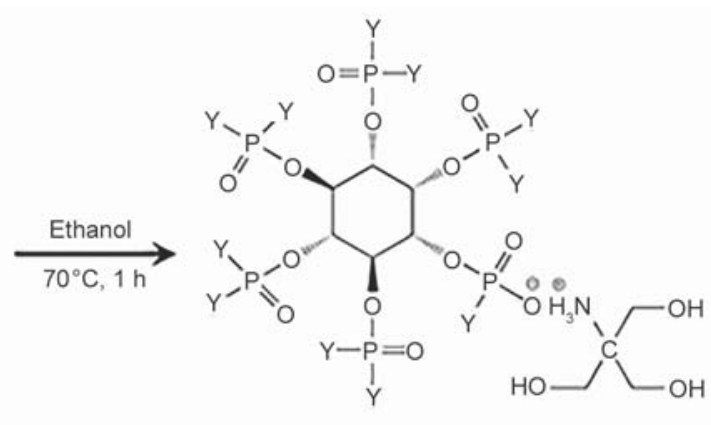

PA-THAM

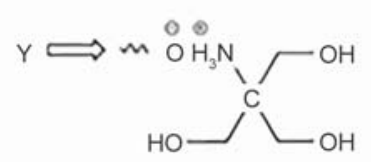

Figure 1. Scheme of possible reaction route between PA and THAM.

Table 1. Formulation of PLA and its biocomposites.

\begin{tabular}{|c|c|c|}
\hline Sample & $\begin{array}{c}\text { PLA } \\
{[\mathbf{w t} \%]}\end{array}$ & $\begin{array}{c}\text { PA-THAM } \\
{[\mathbf{w t} \%]}\end{array}$ \\
\hline B1 & 100 & 0 \\
\hline B2 & 99 & 1 \\
\hline B3 & 97 & 3 \\
\hline B4 & 95 & 5 \\
\hline
\end{tabular}

the standard experimental setup. FTIR curves were recorded by a range of $4000-500 \mathrm{~cm}^{-1}$ on a $\mathrm{KBr}$ powder by using the apparatus (Nicolet iS50).

Thermogravimetric analysis (TGA) was performed on a thermo-analyzer equipment (Q50, TA Instruments) from ambient temperature to $700^{\circ} \mathrm{C}$ at a heating rate of $10^{\circ} \mathrm{C} / \mathrm{min}$ in both $\mathrm{N}_{2}$ and air atmosphere. Fire performance of PLA composites was characterized by limiting oxygen index (LOI), vertical burning test (UL-94), and Cone calorimeter test (CCT). LOI test was conducted on the sample size with $127 \mathrm{~mm} \times 6.5 \mathrm{~mm} \times 3.0 \mathrm{~mm}$ in an oxygen index tester (FTT, UK) according to ASTM D 2863-2013. UL94 Vertical Flame Chamber (FTT, UK) was operated to test specimens with $127 \mathrm{~mm} \times 12.7 \mathrm{~mm} \times 3.0 \mathrm{~mm}$ in accordance with the ASTM D 3801-2010 standard. The surface temperature $\left(T_{\mathrm{s}}\right)$ of PLA and its biocomposite was tested by an infrared thermometer during the combustion test and the emissivity was set at 0.950. As for the CCT (FTT, UK; heat flux at $35 \mathrm{~kW} / \mathrm{m}^{2}$ ), specimen dimension with $100 \mathrm{~mm} \times$ $100 \mathrm{~mm} \times 3.0 \mathrm{~mm}$ was wrapped by aluminum foil and placed on ceramic backing boards with a distance of $25 \mathrm{~mm}$ from the cone base by following ISO 56601-2016. Furthermore, a simulated assay was designed to detect the heating rate of all the formulations during the ignition process in CCT, and two thermocouples were placed on the respective center site of the surface and bottom for each sample.

In order to further investigate the flame-retardant mechanism, thermogravimetric analysis coupled with Fourier transform infrared spectroscopy (TGA-FTIR) was conducted to detect the gaseous products during combustion. Samples were heated from room temperature to $700^{\circ} \mathrm{C}$ at $10^{\circ} \mathrm{C} / \mathrm{min}$ under nitrogen, and the FTIR spectra were collected in the range of 4000$500 \mathrm{~cm}^{-1}$. Fourier transform infrared spectroscopy connected with a heating device was used to characterize the condensed phase with the variable temperature (VT-FTIR). The procedure for heating was set up to $300^{\circ} \mathrm{C}$ with $10^{\circ} \mathrm{C} / \mathrm{min}$ and isothermal for $15 \mathrm{~min}$; meanwhile, FTIR was performed at the same conditions as for TGA-FTIR.

Rheology test was conducted on a stress-controlled rheometer (AR2000EX, TA instruments) equipped with a forced-air convection oven and a parallel plate geometry (diameter $25 \mathrm{~mm}$, gap $1 \mathrm{~mm}$ ) under air atmosphere. Specimens were put between the parallel plates in the frequency of $1 \mathrm{rad} / \mathrm{s}$ and the constant strain of $5 \%$ at the temperature range from 150 to $200^{\circ} \mathrm{C}$.

Tensile test (INSTRON 3384, MA, USA) and Charpy impact test (CEAST impact machine, un-notched) were used to study the mechanical properties of PLA and its composites. The dumbbell tensile samples were shaped according to the ASTM D 638-2014 standard with a crosshead speed of $5 \mathrm{~mm} / \mathrm{min}$. The un-notched specimens for impact tests were hotpressed in accordance with ISO 179-1-2010 standard. Each formulation was tested with five specimens. 


\section{Results and discussion}

\subsection{Characterization of PA-THAM}

NMR and FTIR were employed to characterize the chemical structure of this novel flame-retardant PATHAM (shown in Figure 2 and Figure 3). The protons of hydroxyl groups and ammonium salt in the structure did not appear in the spectrum because they were exchanged with the $\mathrm{D}_{2} \mathrm{O}$ solvent. Therefore, the peak for PA-THAM in ${ }^{1} \mathrm{H}$ NMR at $3.43 \mathrm{ppm}$ was attributed to the protons of the methene groups, while the protons from phytic acid overlapped with the ones from methene group [19]. Moreover, the relevant characteristic peaks were also detected in ${ }^{13} \mathrm{C}$ NMR $\left(\mathrm{D}_{2} \mathrm{O}\right.$, ppm: $\left.74.2,61.3,59.3\right)$ and ${ }^{31} \mathrm{P}$ NMR spectrum $\left(\mathrm{D}_{2} \mathrm{O}, \mathrm{ppm}: 2.28,0.06\right)[20,21]$. As for the FTIR spectra in Figure 3a, the characteristic peaks of PA at 3370, 1638, 1163, and $1003 \mathrm{~cm}^{-1}$ were attributed to the stretching vibration of $\mathrm{O}-\mathrm{H}$, $\mathrm{O}-\mathrm{P}-\mathrm{O}, \mathrm{P}=\mathrm{O}$, and $\mathrm{P}-\mathrm{O}$, respectively. In spectra of THAM, the absorption bands around $3400-3300 \mathrm{~cm}^{-1}$ were assigned to the $\mathrm{N}-\mathrm{H}$ stretching from primary amine group and peaks at 2900,1560, $1020 \mathrm{~cm}^{-1}$ were derived from $-\mathrm{CH}_{2}-$ stretching vibration, $\mathrm{N}-\mathrm{H}$ bending vibration, and $\mathrm{C}-\mathrm{N}$ stretching vibration. In comparison with two raw materials, some new alterations were observed in the spectra of PA-THAM. For example, a broad and strong band appeared at $3400-2500 \mathrm{~cm}^{-1}$ was owing to the formation of an ammonium salt and overlap with ones of $\mathrm{O}-\mathrm{H}$,
$-\mathrm{CH}_{2}-$, which was different from that of PA or THAM alone. Moreover, other characteristic peaks were detected, such as double bands around $1600 \mathrm{~cm}^{-1}$ assigned to $v_{\text {as }}(\mathrm{O}-\mathrm{P}-\mathrm{O})$ and $\beta(\mathrm{N}-\mathrm{H})$ as well as strong absorbance from $1160-960 \mathrm{~cm}^{-1}$ due to the bands from $\mathrm{P}=\mathrm{O}$, and $\mathrm{P}-\mathrm{O}$. These changes in PA-THAM indicated that the reaction occurred between carboxyl and amino groups.

Besides, a comparison of thermal stability between PA, THAM, and PA-THAM was listed in Figure $3 b$. As a compound bearing hydroxyl groups, THAM exhibited a maximum weight loss at $218^{\circ} \mathrm{C}$ and little residue left after $300^{\circ} \mathrm{C}$, which was caused by the evaporation effect above the boiling point. PA started to lose weight below $100{ }^{\circ} \mathrm{C}$ due to the aqueous solution, and other two degradation stages were attributed to carbonization at $300^{\circ} \mathrm{C}$ and char degradation at $600{ }^{\circ} \mathrm{C}$, while only $10 \mathrm{wt} \%$ residue left at $700{ }^{\circ} \mathrm{C}$ [22]. After salt formation, the initial decomposition temperature $T_{5 \%}$ corresponding to $5 \mathrm{wt} \%$ weight loss increased up to $217^{\circ} \mathrm{C}$, and meanwhile, residue increased up to $40 \mathrm{wt} \%$ above $700^{\circ} \mathrm{C}$ due to the stable char-layer formation. As for PA-THAM, the degradation process also consisted of three stages, which was accordingly attributed to dehydration of ionic bond around $150^{\circ} \mathrm{C}$, depolymerization and carbonization at $230^{\circ} \mathrm{C}$, and char degradation at $450^{\circ} \mathrm{C}$. As a consequence of better thermal stability and charring ability than PA, this novel

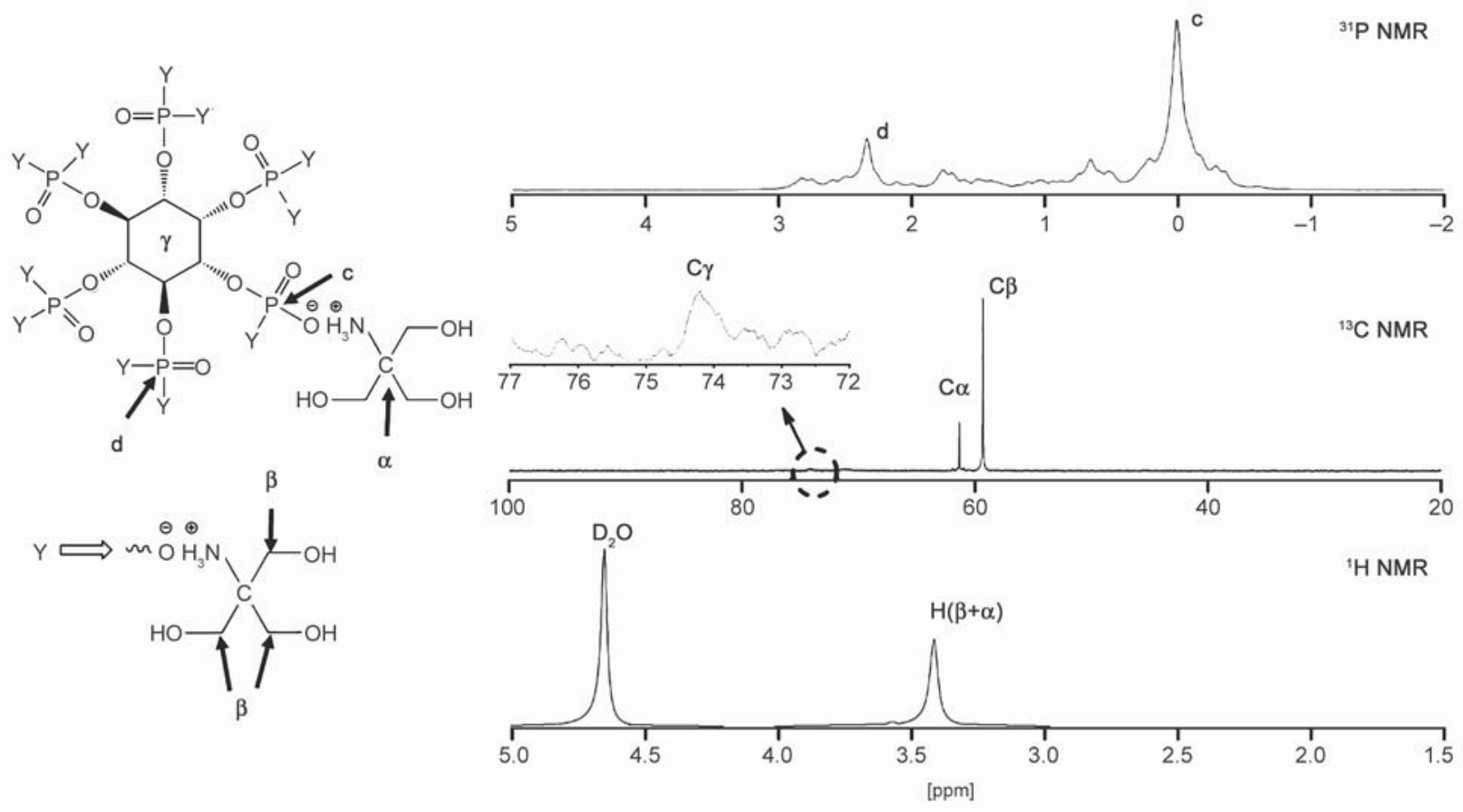

Figure 2. ${ }^{1} \mathrm{H}$ NMR, ${ }^{13} \mathrm{C}$ NMR and ${ }^{31} \mathrm{P}$ NMR spectra for PA-THAM. 

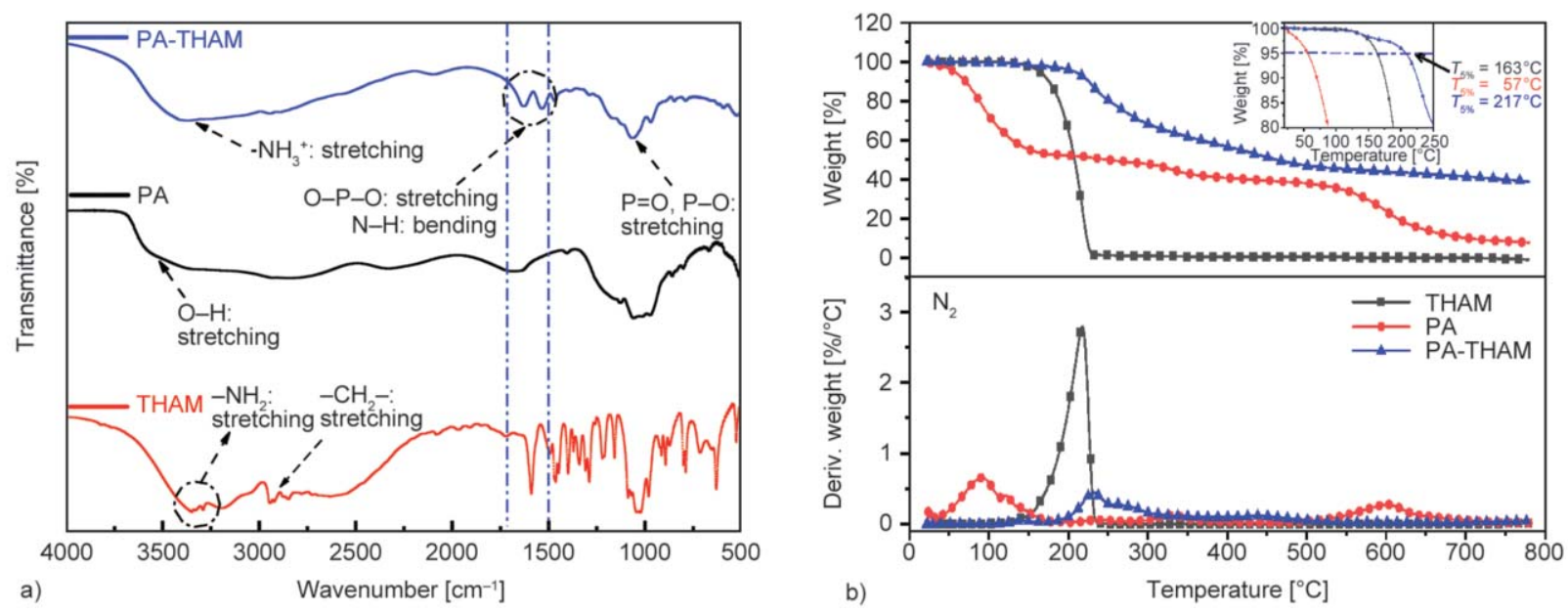

Figure 3. FTIR and TGA spectra for PA, THAM, and PA-THAM: (a) FTIR spectra; (b) TGA spectra.

product PA-THAM can be used as an additive for PLA.

\subsection{Thermal properties}

Thermogravimetric analysis was carried out to assess the thermal and thermal-oxidative decomposition behaviors of PLA and its biocomposites. PLA and its composites underwent a similar decomposition process in both $\mathrm{N}_{2}$ and air conditions (in Figure 4), where $T_{5 \%}$ was observed around $320^{\circ} \mathrm{C}$, whilst the maximum weight loss rate occurred at $350^{\circ} \mathrm{C}$. This similar decomposition behavior under different atmospheres can be explained that the decomposition of PLA biocomposite was not significantly influenced by oxygen. Along with the increasing content of PA-THAM, the value of $T_{5 \%}$ reduced slightly, which was because of the poor thermal stability of PA-THAM caused by dehydration of PATHAM and decomposition of ionic bonds [12].

The decomposition of pure PLA left almost no residue, while its composites with PA-THAM presented slightly higher residue above $400^{\circ} \mathrm{C}$. Besides, the maximum degradation rate was also decreased after

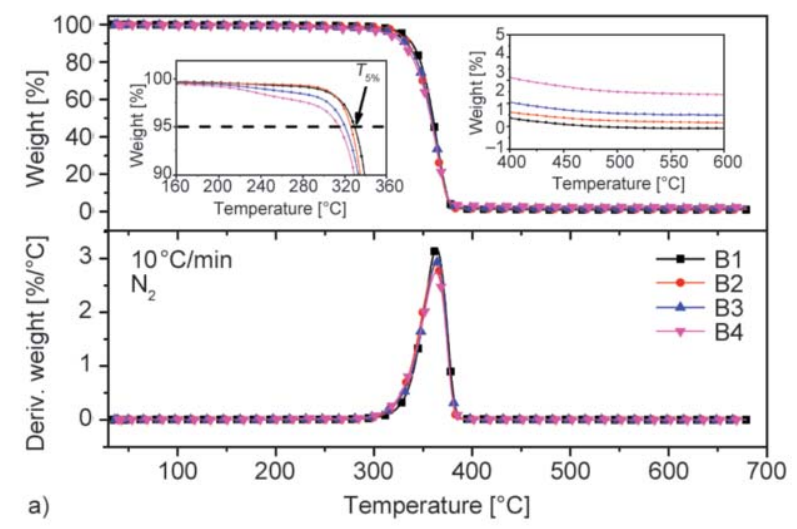

introducing PA-THAM. This was probably due to the carbonization of PA-THAM, which took place at a later stage. According to the theoretical amount of char residue, it can be concluded that the presence of PA-THAM did not favor PLA to have a charring behavior, but the residues played a positive role in the combustion process.

\subsection{LOI and UL-94}

From results, as listed in Table 2, of the LOI and UL94, the flammability of PLA was improved obviously after introducing PA-THAM. Compared with pure PLA with an LOI value of $19.9 \%$ and no rating in UL-94, the formulations with PA-THAM presented a noticeable enhancement. When the load of PATHAM was up to $3 \mathrm{wt} \%$, the LOI value of biocomposite rose up to $25.8 \%$ as well as the $\mathrm{V}-0$ rating was achieved in UL-94. Along with $5 \mathrm{wt} \%$ addition in PLA, an increased LOI value of $27.9 \%$ and V-0 rating in UL-94 were obtained in formulation B4. In comparison with other phosphorus-containing flame retardants [23], which were used in PLA at relatively high concentrations or played a key role in the gas

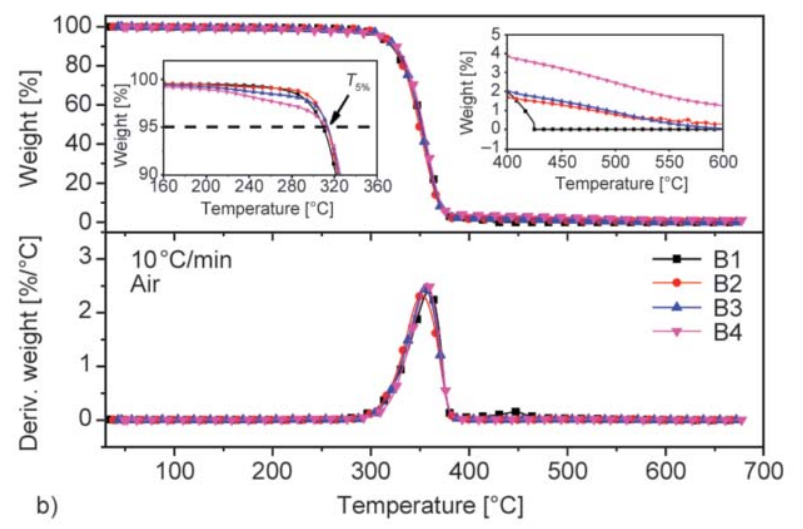

Figure 4. PLA and its biocomposites' TGA curves in (a) nitrogen and (b) air obtained at $10^{\circ} \mathrm{C} / \mathrm{min}$. 
phase via capturing free radicals before ignition, this bio-based phytate PA-THAM endowed PLA with good fire resistance in LOI and UL-94 tests. More impressively, the dripping phenomenon exhibited a significant improvement, where only three droplets were observed during the combustion of $\mathrm{B} 3$ as well as one for B4. Concerning formulations B3 and B4, they were hard to be ignited and flamed out quickly after removing the igniter in UL-94; therefore, consequences of $\mathrm{V}-0$ rating were obtained.

Aiming to explain this 'anti-dripping' ability, the change of surface temperature $\left(T_{\mathrm{s}}\right)$ for neat PLA and its biocomposite B3 during combustion was listed in Figure 5 . The $T_{\mathrm{s}}$ of neat PLA continuously rose to $370^{\circ} \mathrm{C}$ after the first ignition that lasted for $30 \mathrm{~s}$, and then burned out after the second ignition. However, an interesting self-extinguishing behavior was observed in formulation B3, in which there was no flame at the first $10 \mathrm{~s}$ and the $T_{\mathrm{s}}$ only went up to a maximum of $290^{\circ} \mathrm{C}$ in the second ignition. This was because the incorporation of PA-THAM led to the 'heat transfer' effect, which facilitated the surface heat of the sample to transfer to other parts quickly. Finally, the $T_{\mathrm{s}}$ decreased and the further flame reaction was prevented. Besides, the flammability performance of B3 biocomposite was also recorded by the screenshots, which demonstrated almost no flame in the whole UL-94 process. These satisfactory results from LOI and UL-94 were further investigated in the following tests.

\subsection{Cone calorimeter test}

Cone calorimeter test (CCT) is a bench-scale method, which is usually applied to simulate the combustion behavior of materials under developing fire scenarios [24]. Some important parameters are collected, such as heat release rate (HRR), peak heat release rate (PHRR), total heat release rate (THR), time to ignition (TTI), average effective heat of combustion (AvEHC) and mass loss, etc. The detailed information from the CCT was listed in Table 3 and Figure 6.

In comparison with pure PLA, which is susceptible to combustion and almost burned up after the test $\left(410 \mathrm{~kW} / \mathrm{m}^{2}\right.$ for PHRR and $0.6 \mathrm{wt} \%$ for residue), the other formulations demonstrated better flame-retardant properties. Biocomposite B3 exhibited that PHRR value decreased to $366 \mathrm{~kW} / \mathrm{m}^{2}$, residue rose up to $2.5 \mathrm{wt} \%$, and a slight improvement was observed for THR and Av-EHC. This was due to the charring ability from PA-THAM at a higher temperature to act physical obstruction, which can be seen in the digital photos from Figure 6c [25]. Moreover,

Table 2. Flame retardant properties of PLA and its biocomposites.

\begin{tabular}{|c|c|c|c|c|c|}
\hline \multirow[b]{2}{*}{ Sample } & \multirow{2}{*}{$\begin{array}{l}\text { LOI } \\
{[\%]}\end{array}$} & \multicolumn{4}{|c|}{ UL-94 } \\
\hline & & Rating & $\begin{array}{l}\overline{t_{1} / t_{2}} \\
{[\mathbf{s}]}\end{array}$ & $\begin{array}{c}\text { Dripping/ } \\
\text { (droplets/ } 20 \text { s) }\end{array}$ & Ignition \\
\hline B1 & $19.9 \pm 0.2$ & no rating & burned all & serious & YES \\
\hline B2 & $23.0 \pm 0.2$ & $\mathrm{~V}-2$ & $18 / 3$ & 21 & YES \\
\hline B3 & $25.8 \pm 0.2$ & $\mathrm{~V}-0$ & $1 / 1$ & 3 & $\mathrm{NO}$ \\
\hline B4 & $27.9 \pm 0.2$ & $\mathrm{~V}-0$ & $0 / 1$ & 1 & $\mathrm{NO}$ \\
\hline
\end{tabular}

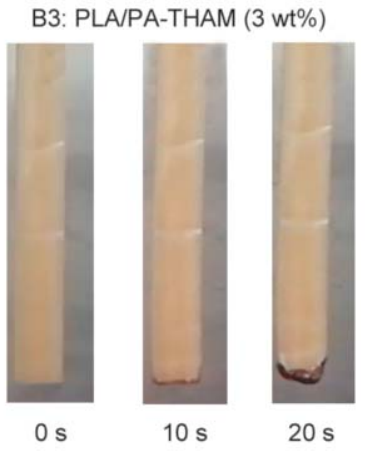

a)

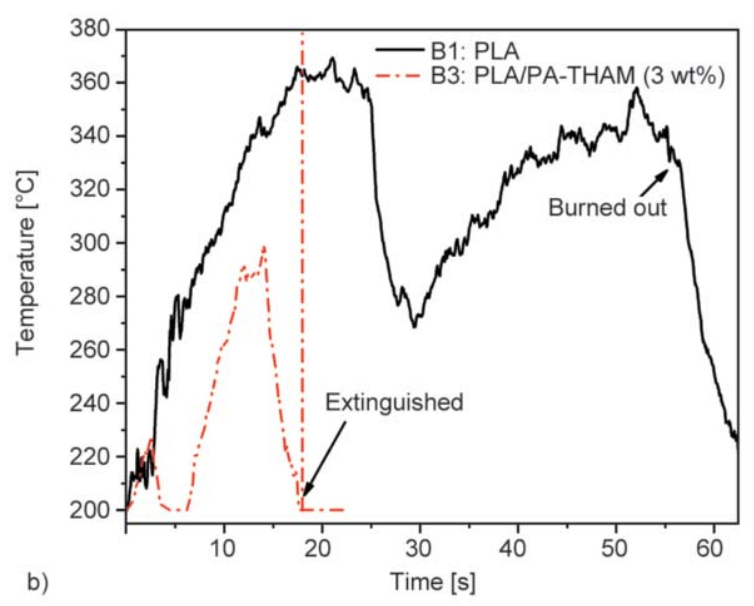

Figure 5. Results for PLA and its biocomposite from the UL-94 test: (a) screenshots during the UL-94 test; (b) Temperature $v s$. Time curves at surface position. 
according to the flame retardant index (FRI) [26], which defined a criterion for the effect of different additives on the flame retardant properties of thermoplastics, samples with PA-THAM exhibited a FRI value between 1 and 10 , as well as this value increased with the percentage of PA-THAM from 1.18 to 1.75 . Therefore, the incorporation of PA-THAM enabled PLA-based biocomposite to achieve a 'good' flame retardancy level [27]. The FRI was calculated according to Equation (1) and the corresponding value was listed in Table 3 .

FRI $=\frac{\left[T H R \cdot\left(\frac{P H R R}{T T I}\right)\right]_{\text {neat polymer }}}{\left[T H R \cdot\left(\frac{P H R R}{T T I}\right)\right]_{\text {composite }}}$

In addition, an ignition-delay result was observed in TTI after incorporating PA-THAM, which was related to physical and chemical factors. Due to little effect of PA-THAM on the thermal degradation process of the material, the chemical factors involved species and concentration of degradation volatiles can be negligible. As for physical factors, the temperature-rising rate was considered to play an important role in this system during the ignition process. In order to investigate this parameter, the relationship between ignition temperature and ignition time was studied for PLA and its biocomposites. From Figure $7 \mathrm{a}$, all the formulations were ignited at the same temperature $334^{\circ} \mathrm{C}$, while the time reached to ignition temperature presented different values, which showed an upward trend from B1 to B4. Meanwhile, the variation in the temperature-rising curves of bottom demonstrated an opposite trend, in which the sequence of temperature value at the same

Table 3. Data from cone calorimeter test for PLA and its biocomposites.

\begin{tabular}{|l|c|c|c|c|c|c|}
\hline \multicolumn{1}{|c|}{ Sample } & $\begin{array}{c}\text { PHRR } \\
{\left[\mathbf{k W} / \mathbf{m}^{2}\right]}\end{array}$ & $\begin{array}{c}\text { TTI } \\
{[\mathbf{s}]}\end{array}$ & $\begin{array}{c}\text { THR } \\
{\left[\mathbf{M J} / \mathbf{m}^{2}\right]}\end{array}$ & $\begin{array}{c}\text { Av-EHC } \\
{[\mathbf{M J} / \mathbf{k g}]}\end{array}$ & $\begin{array}{c}\text { Residue } \\
{[\mathbf{w t} \%]}\end{array}$ & FRI \\
\hline B1 & $410 \pm 5$ & $61 \pm 1$ & $70 \pm 1$ & $15.7 \pm 0.1$ & $0.6 \pm 0.2$ & - \\
\hline B2 & $379 \pm 4$ & $65 \pm 2$ & $68 \pm 1$ & $15.6 \pm 0.2$ & $1.1 \pm 0.1$ & 1.18 \\
\hline B3 & $366 \pm 3$ & $71 \pm 1$ & $64 \pm 1$ & $15.5 \pm 0.1$ & $2.5 \pm 0.2$ & 1.42 \\
\hline B4 & $349 \pm 5$ & $73 \pm 2$ & $56 \pm 1$ & $14.5 \pm 0.2$ & $4.9 \pm 0.5$ & 1.75 \\
\hline
\end{tabular}
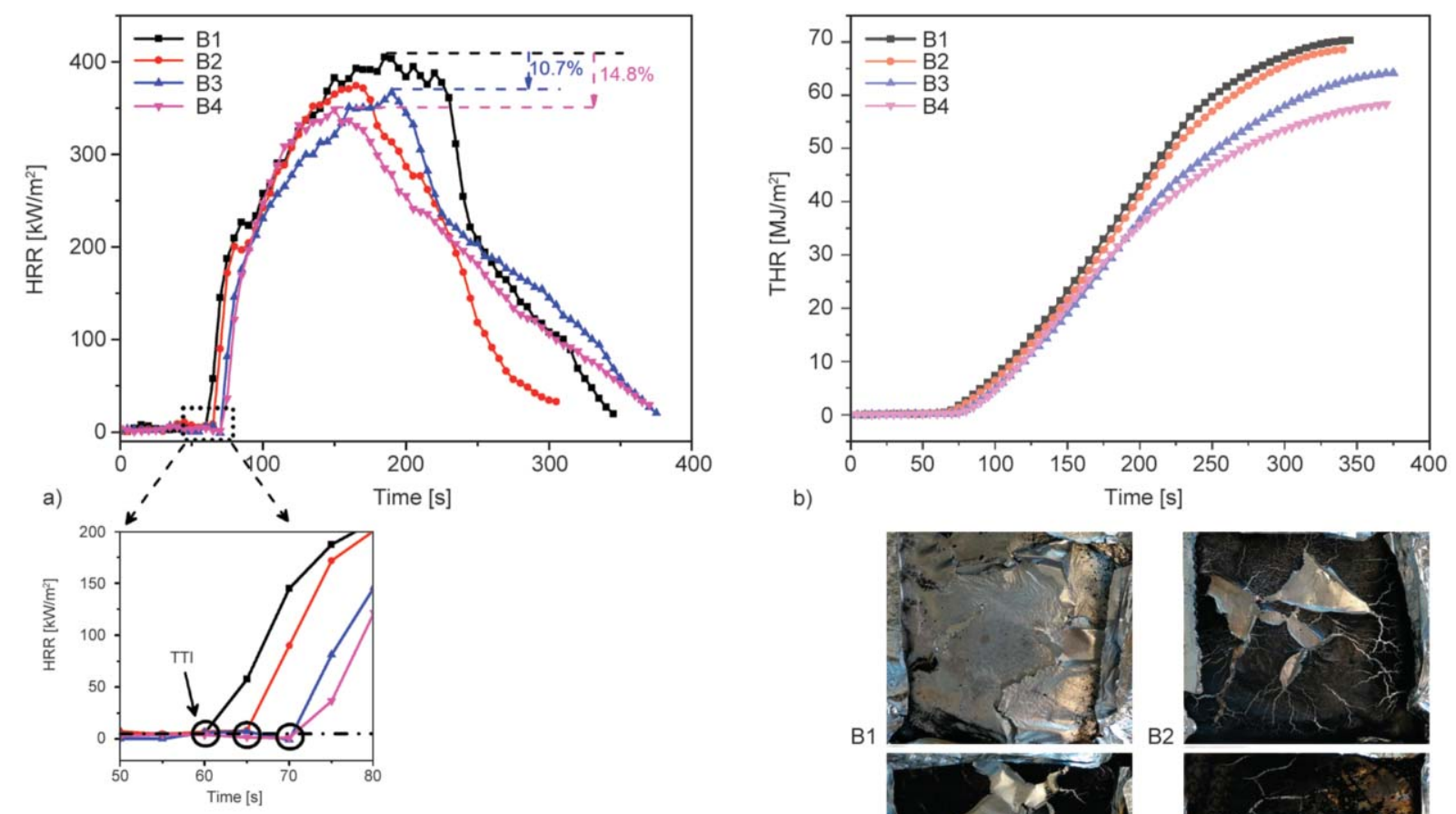

b)

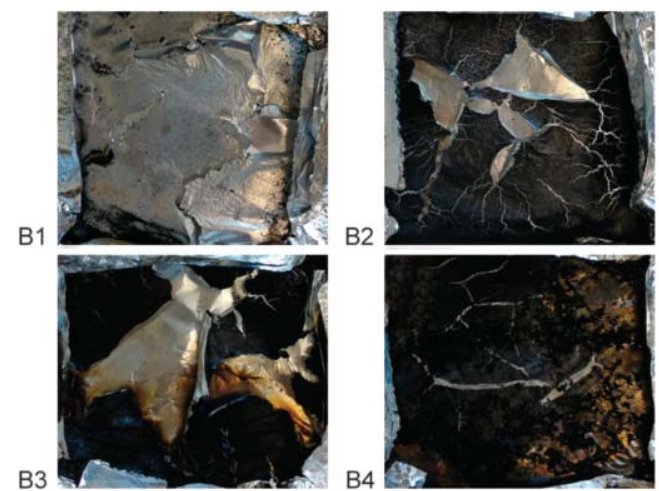

Figure 6. Results of PLA and its biocomposites after cone calorimeter test: (a) HRR vs. Time curves; (b) THR vs. Time curves; (c) digital photos after combustion: B1) PLA, B2) PLA/PA-THAM 1 wt \%, B3) PLA/PA-THAM 3 wt $\%$, B4) PLA/PA-THAM 5 wt $\%$. 

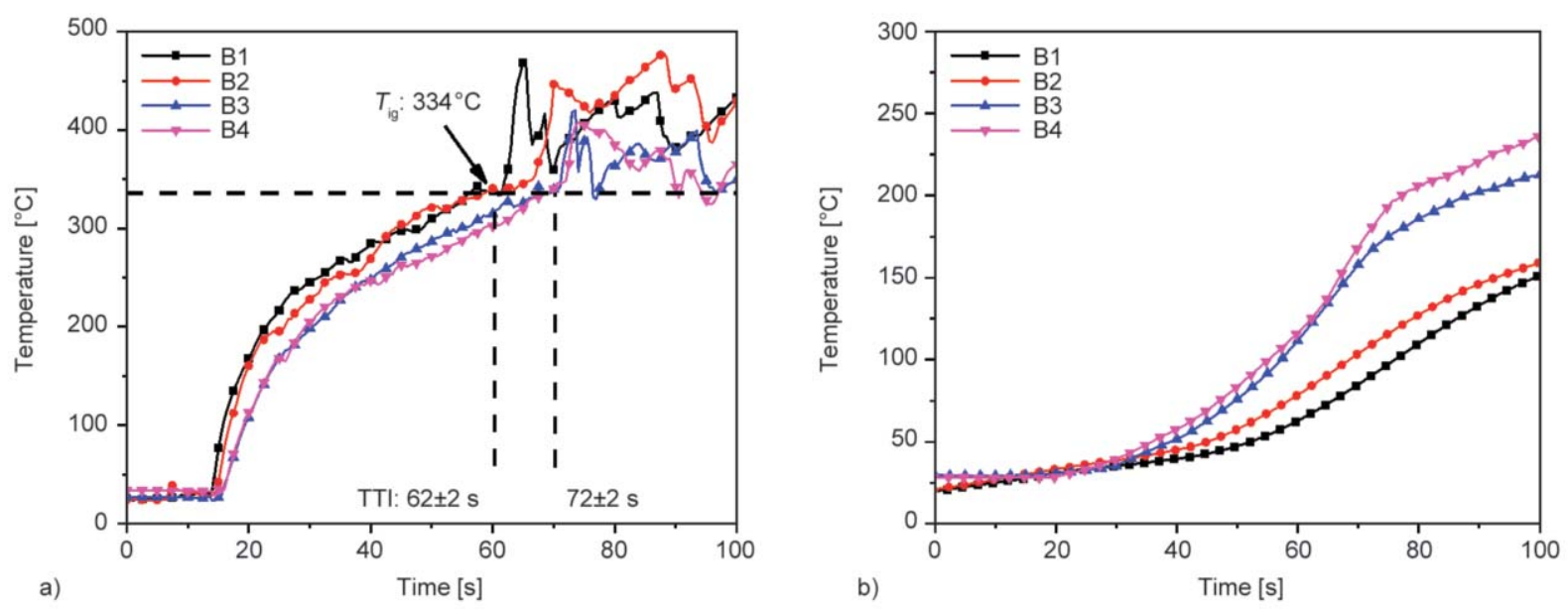

Figure 7. Curves between temperature and time before ignition during the cone calorimeter test: (a) Temperature vs. Time curves at top position; (b) Temperature vs. Time curves at bottom position.

time was: $\mathrm{B} 4>\mathrm{B} 3>\mathrm{B} 2>\mathrm{B} 1$. This was because the introduction of PA-THAM decreased the molten viscosity of the material system, which promoted the 'heat transferl' in-depth of sample and reduced the temperature-rising rate of surface, consequently delayed the ignition time [28, 29].

In order to investigate the effect of PA-THAM on molten viscosity of the material system, rheological characterization was carried out to analyze the molten flow behavior of materials without affecting their microstructure [30]. The complex viscosity at different temperatures for all the formulations was exhibited in Figure 8. With regard to neat PLA, which was known as Newtonian plateau [31], the viscosity was $15000 \mathrm{~Pa} \cdot \mathrm{s}$ at $155^{\circ} \mathrm{C}$ and the value decreased with increasing temperature. In contrast, biocomposite with $3 \mathrm{wt} \%$ PA-THAM exhibited remarkably low initial complex viscosity with $2500 \mathrm{~Pa} \cdot \mathrm{s}$ at $155^{\circ} \mathrm{C}$, while this molten value still kept lower than that of

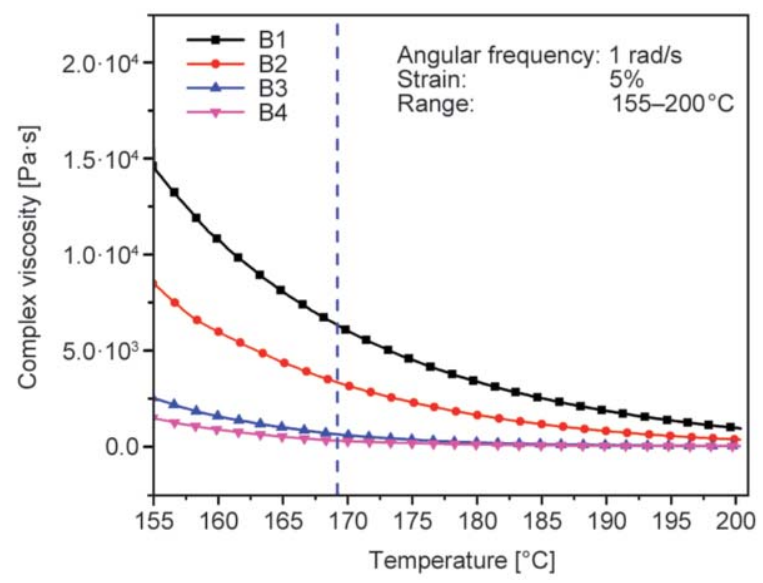

Figure 8. Rheology behaviour of PLA and its biocomposites at different temperatures: Complex viscosity vs. Temperature. pure PLA at $170^{\circ} \mathrm{C}$, which varied from 5973 to $570 \mathrm{~Pa} \cdot \mathrm{s}$. This change can be elucidated that PA-THAM, as a comparatively small amount of low molecular weight additive in the PLA matrix, played a lubricating role in this binary system, which can weaken the intermolecular forces to decrease the molten viscosity significantly $[32,33]$. Moreover, this reduction can be a good indication to decrease the processing temperature for PLA.

\subsection{Proposed flame retardant mechanism}

To investigate the gaseous phase action of thermal degradation for biocomposite with PA-THAM, the TGA-FTIR technique was conducted to analyze the evolved volatile products from PLA and PLA/PATHAM (3 wt $\%$ ) during the thermal decomposition. From the Figure 9a, PLA and PLA/PA-THAM system presented almost similar evolved gas products [34], which meant a few amounts of PA-THAM hardly altered the main decomposition behavior of PLA except peaks from $2358 \mathrm{~cm}^{-1}\left(\mathrm{CO}_{2}\right)$ and $1244 \mathrm{~cm}^{-1}$ (C-O stretching), respectively.

Furthermore, for both PLA and PLA/PA-THAM, curves of relative intensity as a function of temperature for total gas products absorption and peak at $1244 \mathrm{~cm}^{-1}$ were also listed in Figure $9 \mathrm{~b}$ and $9 \mathrm{c}$. There was almost no difference for total gas products release after introducing PA-THAM into PLA, while the total intensity of $\mathrm{C}-\mathrm{O}$ absorbance was obviously reduced and delayed, which indicated that the ether compounds declined due to the charring effect of PA-THAM at high temperature [35].

Various temperatures connected FTIR were experimented to research the condensed phase of PLA and its biocomposite during the thermo-oxidative 

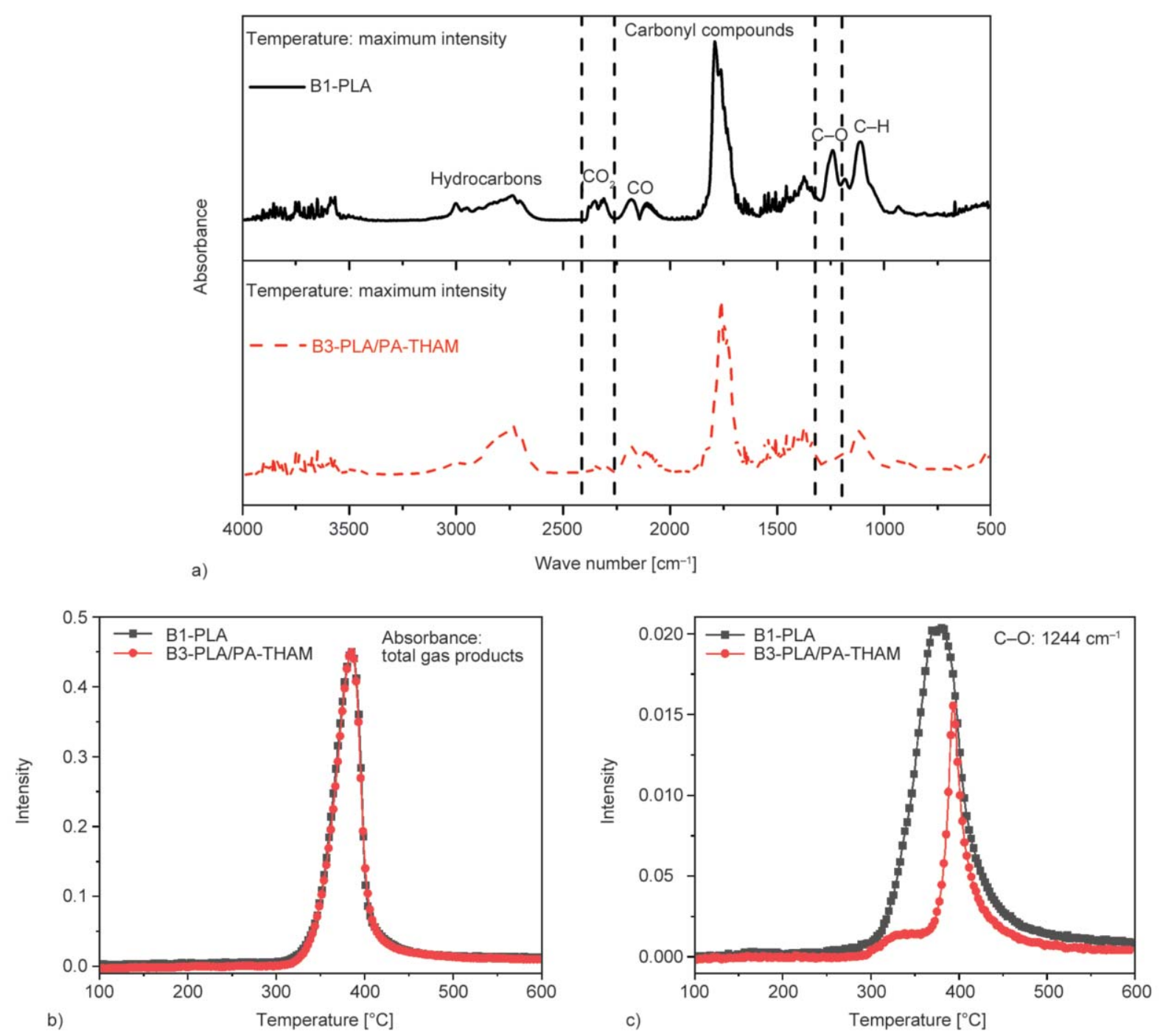

Figure 9. TGA-FTIR spectra of decomposed products for PLA and PLA/PA-THAM: (a) comparison of evolved gas for PLA and PLA/PA-THAM (3 wt \%) at maximum intensity; (b) Intensity $v s$. Temperature curves from total decomposed gas for PLA and PLA/PA-THAM (3 wt\%); (c) Intensity at $1244 \mathrm{~cm}^{-1} v s$. Temperature curves for PLA and PLA/PA-THAM (3 wt $\%)$.

degradation process. Figure 10 exhibited the characteristic absorbance at different times at $300{ }^{\circ} \mathrm{C}$ for PLA and PLA/PA-THAM (3 wt\%). Although both systems showed a similar trend that the intensity of absorption peaks reduced with the increasing time at the testing conditions [36, 37], the incorporation of PA-THAM obviously changed the degradation behaviors at higher temperatures. There were barely peaks after $10 \mathrm{~min}$ at $300^{\circ} \mathrm{C}$ for neat PLA, while the skeleton absorptions and relative spectra intensities were still observed easily in PLA/PA-THAM system. Besides, it was hard to detect the peaks from phosphorus-containing bands due to the small loading of flame retardant.

Based on the previous report [38], the dominant degradation of PLA was comprised of intra- and intermolecular ester exchange, cis-elimination, radical and concerted non-radical reactions, and selective depolymerization. In these two material systems, ester exchange and cis-elimination were also considered as principle reversible reactions despite the addition of PA-THAM. Therefore, the small addition of flame retardant in PLA did not change the thermal decomposition of the material significantly.

In accordance with the analysis of gaseous and condensed phases as well as the results from flame combustion tests, a possible flame-retardant mechanism of PA-THAM can be proposed as following. At the early stage, some incombustible products, such as $\mathrm{H}_{2} \mathrm{O}$, which derived from the dehydration of PATHAM and decomposition of ionic bonds, released into the gas phase. Meanwhile, other pyrolyzed acid 

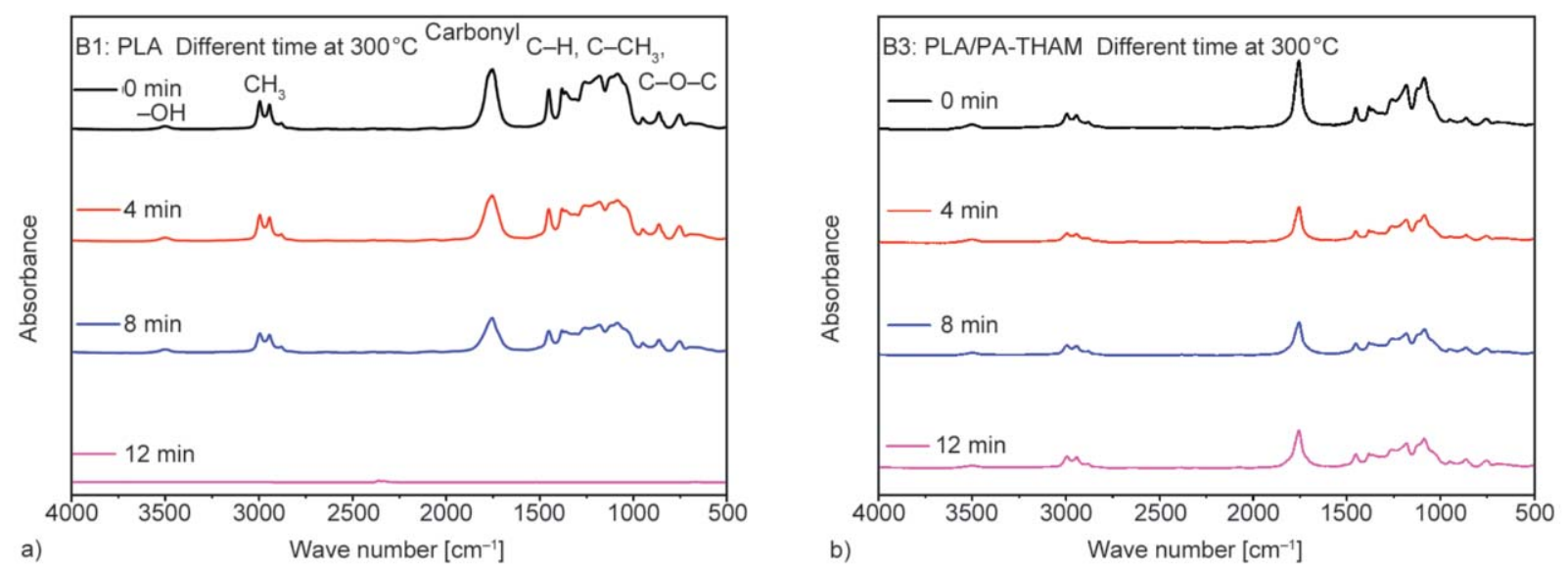

Figure 10. FTIR spectra of pyrolysis products from different time at $300^{\circ} \mathrm{C}$ for PLA and PLA/PA-THAM: (a) Absorbance vs. Wave number curves from different time at $300^{\circ} \mathrm{C}$ for $\mathrm{B} 1 \mathrm{PLA}$; (b) Absorbance $v s$. Wave number curves from different time at $300{ }^{\circ} \mathrm{C}$ for B3 PLA/PA-THAM (3 wt $\%$ ).

compounds promoted the thermal degradation of PLA, which can cause the reduction of molten viscosity and facilitate the heat transfer. Along with further decomposition, the carbonization of PA-THAM led to forming a protective layer in the condensed phase. As a consequence, the flame-retardant mechanism of PA-THAM mainly focused on the combination of 'heat transfer' effect, dilution action and slight barrier protection by physical properties.

\subsection{Mechanical properties}

The effect of PA-THAM on the mechanical properties of PLA was studied as well, and the results from tensile and impact tests were summarized in Table 4 . The load of PA-THAM up to $3 \mathrm{wt} \%$ had a slight impact on the tensile properties. By introducing $3 \mathrm{wt} \%$ of PATHAM into PLA, the tensile strength only decreased from 67.3 to $64.8 \mathrm{MPa}$. Moreover, no reduction in the elongation at break was observed, whilst there was little effect on the impact strength with the value varied from 23.6 to $23.8 \mathrm{KJ} / \mathrm{m}^{2}$. However, as the weight percentage of PA-THAM in PLA increased to $5 \mathrm{wt} \%$, a reduction in both tensile and impact strength were obtained. This alteration was probably attributed to the results from some adverse impacts of additive on the

Table 4. Mechanical properties of PLA and its biocomposites.

\begin{tabular}{|l|c|c|c|}
\hline \multicolumn{1}{|c|}{ Sample } & $\begin{array}{c}\text { Elongation at } \\
\text { break } \\
{[\%]}\end{array}$ & $\begin{array}{c}\text { Tensile stress } \\
{[\mathbf{M P a}]}\end{array}$ & $\begin{array}{c}\text { Impact } \\
\text { strength } \\
{\left[\mathbf{k J} / \mathbf{m}^{2}\right]}\end{array}$ \\
\hline B1 & $4.1 \pm 0.1$ & $67.3 \pm 1.5$ & $23.6 \pm 2.0$ \\
\hline B2 & $4.1 \pm 0.1$ & $65.3 \pm 2.0$ & $22.3 \pm 1.0$ \\
\hline B3 & $4.1 \pm 0.1$ & $64.8 \pm 1.5$ & $23.8 \pm 2.0$ \\
\hline B4 & $3.9 \pm 0.2$ & $60.2 \pm 1.0$ & $15.0 \pm 2.0$ \\
\hline
\end{tabular}

crystallization and molecular weight of PLA and indicated PA-THAM in PLA would maintain the mechanical properties at optimum load levels.

\section{Conclusions}

In this study, a novel bio-based flame retardant (PATHAM) was synthesized successfully via salt formation reaction between phytic acid and trometamol. After introducing only $3 \mathrm{wt} \%$ loading of PA-THAM into PLA, some improvements were obtained in LOI and UL-94 tests. In contrast with neat PLA, this formulation B3 demonstrated a higher LOI value $(25.8 \%)$, as well as passed UL-94 V-0 rating. An ignition-resistance performance of sample B3 was also observed during combustion, such as self-extinguishing and ignition-delay. These phenomena were investigated via self-designed experiments, and the results elucidated that the existence of PA-THAM significantly decreased the molten viscosity of biocomposite by $90 \%$ at $170^{\circ} \mathrm{C}$, which promoted the 'heattransfer' effect to reduce the surface temperature during the combustion process. Furthermore, the incorporation of $3 \mathrm{wt} \%$ PA-THAM endowed sample B3 with $1.42 \mathrm{FRI}$ value, and the predominant flame-retardant mechanism played a role in the condensed phase by a combination of physical properties. In comparison with pure PLA, the same loading of PATHAM did little effect on the mechanical properties, such as the same value for elongation at break, a variation of tensile strength from 67.3 to $64.8 \mathrm{MPa}$, little change for impact strength from 23.6 to $23.8 \mathrm{KJ} / \mathrm{m}^{2}$. However, further $5 \mathrm{wt} \%$ incorporation of PA-THAM in PLA exhibited slight enhancements in flame retardant performance, while the mechanical properties 
decreased obviously. Therefore, this novel bio-based phytate PA-THAM can maintain the balance of good flame retardancy performance and mechanical properties of PLA biocomposite at optimum loads.

\section{Acknowledgements}

This research was partly funded by Spanish Ministry of Economy and Competitiveness (MINECO) under the project BIA2017-88401-R AEI/FEDER/UE, and under Ramón y Cajal fellowship (RYC-2012-10737), Joint Research Fund for Overseas Chinese, Hong Kong and Macao Young Scholars (51929301) and China Scholarship Council (No.201608310142). The authors would like to give a great appreciation to Dr. Zhiqi Liu, Dr. Zhi Li and Dr.Shuang Hu for their contributions to this work.

\section{References}

[1] Dahy H.: Biocomposite materials based on annual natural fibres and biopolymers - Design, fabrication and customized applications in architecture. Construction and Building Materials, 147, 212-220 (2017). https://doi.org/10.1016/j.conbuildmat.2017.04.079

[2] Kim I., Viswanathan K, Kasi G., Sadeghi K., Thanakkasaranee S., Seo J.: Poly(lactic acid)/ZnO bionanocomposite films with positively charged $\mathrm{ZnO}$ as potential antimicrobial food packaging materials. Polymers, 11, 1-17 (2019).

https://doi.org/10.3390/polym11091427

[3] Ahmad A. F., Ab Aziz S., Abbas Z., Obaiys S. J., Matori K. A., Zaid M. H. M., Raad H. K., Aliyu U. S.: Chemically reduced graphene oxide-reinforced poly(lactic acid)/poly(ethylene glycol) nanocomposites: Preparation, characterization, and applications in electromagnetic interference shielding. Polymers, 11, 661/1661/20 (2019).

https://doi.org/10.3390/polym11040661

[4] Macha I. J., Ben-Nissan B., Santos J., Cazalbou S., Stamboulis A., Grossin D., Giordano G.: Biocompatibility of a new biodegradable polymer-hydroxyapatite composite for biomedical applications. Journal of Drug Delivery Science and Technology, 38, 72-77 (2017). https://doi.org/10.1016/j.jddst.2017.01.008

[5] Farah S., Anderson D. G., Langer R.: Physical and mechanical properties of PLA, and their functions in widespread applications - A comprehensive review. Advanced Drug Delivery Reviews, 107, 367-392 (2016). https://doi.org/10.1016/j.addr.2016.06.012

[6] Csikós Á., Faludi G., Domján A., Renner K., Móczó J., Pukánszky B.: Modification of interfacial adhesion with a functionalized polymer in PLA/wood composites. European Polymer Journal, 68, 592-600 (2015). https://doi.org/10.1016/j.eurpolymj.2015.03.032

[7] Costes L., Laoutid F., Aguedo M., Richel A., Brohez S., Delvosalle C., Dubois P.: Phosphorus and nitrogen derivatization as efficient route for improvement of lignin flame retardant action in PLA. European Polymer Journal, 84, 652-667 (2016).

https://doi.org/10.1016/j.eurpolymj.2016.10.003
[8] Yang Y., Haurie L., Wen J., Zhang S., Ollivier A., Wang D-Y.: Effect of oxidized wood flour as functional filler on the mechanical, thermal and flame-retardant properties of polylactide biocomposites. Industrial Crops and Products, 130, 301-309 (2019).

https://doi.org/10.1016/j.indcrop.2018.12.090

[9] Zhao X., Guerrero F. R., Llorca J., Wang D-Y.: New superefficiently flame-retardant bioplastic poly(lactic acid): Flammability, thermal decomposition behavior, and tensile properties. ACS Sustainable Chemistry and Engineering, 4, 202-209 (2016).

https://doi.org/10.1021/acssuschemeng.5b00980

[10] Xia L., Jian R-K., Ai Y-F., Zheng X-L., Zhao B.: An effective multi-hydroxy-containing ammonium phosphate towards flame-retarding poly(lactic acid): Flame retardance, thermal and pyrolysis behaviors. Journal of Analytical and Applied Pyrolysis, 134, 265-273 (2018). https://doi.org/10.1016/j.jaap.2018.06.016

[11] Li Z., Fernández Expósito D., Jiménez González A., Wang D-Y.: Natural halloysite nanotube based functionalized nanohybrid assembled via phosphorus-containing slow release method: A highly efficient way to impart flame retardancy to polylactide. European Polymer Journal, 93, 458-470 (2017).

https://doi.org/10.1016/j.eurpolymj.2017.06.021

[12] Gao Y-Y., Deng C., Du Y-Y., Huang S-C., Wang Y-Z.: A novel bio-based flame retardant for polypropylene from phytic acid. Polymer Degradation and Stability, 161, 298-308 (2019). https://doi.org/10.1016/j.polymdegradstab.2019.02.005

[13] Laoutid F., Vahabi H., Shabanian M., Aryanasab F., Zarrintaj P., Saeb M. R.: A new direction in design of bio-based flame retardants for poly(lactic acid). Fire and Materials, 42, 914-924 (2018).

https://doi.org/10.1002/fam.2646

[14] Vahabi H., Shabanian M., Aryanasab F., Mangin R., Laoutid F., Saeb M. R.: Inclusion of modified lignocellulose and nano-hydroxyapatite in development of new bio-based adjuvant flame retardant for poly(lactic acid). Thermochimica Acta, 666, 51-59 (2018). https://doi.org/10.1016/j.tca.2018.06.004

[15] Jiang P., Zhang S., Bourbigot S., Chen Z., Duquesne S., Casetta M.: Surface grafting of sepiolite with a phosphaphenanthrene derivative and its flame-retardant mechanism on PLA nanocomposites. Polymer Degradation and Stability, 165, 68-79 (2019). https://doi.org/10.1016/j.polymdegradstab.2019.04.012

[16] Vahabi H., Shabanian M., Aryanasab F., Laoutid F., Benali S., Saeb M. R., Seidi F., Kandola B. K.: Three in one: $\beta$-cyclodextrin, nanohydroxyapatite, and a nitrogen-rich polymer integrated into a new flame retardant for poly (lactic acid). Fire and Materials, 42, 593-602 (2018). https://doi.org/10.1002/fam.2513

[17] Zhou Y., Ding C., Qian X., An X.: Further improvement of flame retardancy of polyaniline-deposited paper composite through using phytic acid as dopant or codopant. Carbohydrate Polymers, 115, 670-676 (2015). https://doi.org/10.1016/j.carbpol.2014.09.025 
[18] Costes L., Laoutid F., Brohez S., Delvosalle C., Dubois P.: Phytic acid-lignin combination: A simple and efficient route for enhancing thermal and flame retardant properties of polylactide. European Polymer Journal, 94, 270-285 (2017).

https://doi.org/10.1016/j.eurpolymj.2017.07.018

[19] Barrientos L., Scott J. J., Murthy P. P. N.: Specificity of hydrolysis of phytic acid by alkaline phytase from lily pollen. Plant Physiology, 106, 1489-1495 (1994). https://doi.org/10.1104/pp.106.4.1489

[20] Champagne E. T., Fisher M. S., Hinojosa O.: NMR and ESR studies of interactions among divalent cations, phytic acid, and $\mathrm{N}$-acetyl-amino acids. Journal of Inorganic Biochemistry, 38, 199-215 (1990). https://doi.org/10.1016/0162-0134(90)84013-F

[21] Li D-F., Zhao X., Jia Y-W., Wang X-L., Wang Y-Z.: Tough and flame-retardant poly(lactic acid) composites prepared via reactive blending with biobased ammonium phytate and in situ formed crosslinked polyurethane. Composites Communications, 8, 52-57 (2018). https://doi.org/10.1016/j.coco.2018.04.001

[22] Daneluti A. L. M., do Rosario Matos J.: Study of thermal behavior of phytic acid. Brazilian Journal of Pharmaceutical Sciences, 49, 275-283 (2013). https://doi.org/10.1590/S1984-82502013000200009

[23] Chow W. S., Teoh E. L., Karger-Kocsis J.: Flame retarded poly(lactic acid): A review. Express Polymer Letters, 12, 396-417 (2018).

https://doi.org/10.3144/expresspolymlett.2018.34

[24] Kiliaris P., Papaspyrides C. D.: Polymer/layered silicate (clay) nanocomposites: An overview of flame retardancy. Progress in Polymer Science, 35, 902-958 (2010). https://doi.org/10.1016/j.progpolymsci.2010.03.001

[25] Qin H., Zhang S., Zhao C., Hu G., Yang M.: Flame retardant mechanism of polymer/clay nanocomposites based on polypropylene. Polymer, 46, 8386-8395 (2005).

https://doi.org/10.1016/j.polymer.2005.07.019

[26] Vahabi H., Kandola B. K., Saeb M. R.: Flame retardancy index for thermoplastic composites. Polymers, 11, 1-10 (2019). https://doi.org/10.3390/polym11030407

[27] Vahabi H., Laoutid F., Movahedifar E., Khalili R., Rahmati N., Vagner C., Cochez M., Brison L., Ducos F., Ganjali M. R., Saeb M. R.: Description of complementary actions of mineral and organic additives in thermoplastic polymer composites by flame retardancy index. Polymers for Advanced Technologies, 30, 2056-2066 (2019).

https://doi.org/10.1002/pat.4638
[28] Kashiwagi T., Omori A.: Effects of thermal stability and melt viscosity of thermoplastics on piloted ignition (1). Symposium (International) on Combustion, 22, 13291338 (1989). https://doi.org/10.1016/S0082-0784(89)80144-4

[29] Lai F. C., Kulacki F. A.: The effect of variable viscosity on convective heat transfer along a vertical surface in a saturated porous medium. International Journal of Heat and Mass Transfer, 33, 1028-1031 (1990).

https://doi.org/10.1016/0017-9310(90)90084-8

[30] Marosföi B., Matko S., Anna P., Marosi Gy.: Fire retarded polymer nanocomposites. Current Applied Physics, 6, 259-261 (2006).

https://doi.org/10.1016/j.cap.2005.07.052

[31] Spiridon I., Paduraru O. M., Zaltariov M. F., Darie R. $\mathrm{N}$.: Influence of keratin on polylactic acid/chitosan composite properties. Behavior upon accelerated weathering. Industrial and Engineering Chemistry Research, 52, 9822-9833 (2013). https://doi.org/10.1021/ie400848t

[32] Han C. D., Yu T. C.: Rheological properties of molten polymers. II. Two-phase systems. Journal of Applied Polymer Science, 15, 1163-1180 (1971). https://doi.org/10.1002/app.1971.070150512

[33] Han C. D., Yu T. C.: Rheological behavior of two-phase polymer melts. Polymer Engineering and Science, 12, 81-90 (1972). https://doi.org/10.1002/pen.760120203

[34] Zou H., Yi C., Wang L., Liu H., Xu W.: Thermal degradation of poly(lactic acid) measured by thermogravimetry coupled to fourier transform infrared spectroscopy. Journal of Thermal Analysis and Calorimetry, 97, 929935 (2009).

https://doi.org/10.1007/s10973-009-0121-5

[35] Wei P., Bocchini S., Camino G.: Nanocomposites combustion peculiarities. A case history: Polylactide-clays. European Polymer Journal, 49, 932-939 (2013). https://doi.org/10.1016/j.eurpolymj.2012.11.010

[36] Thanki P. N., Edith D., Six J-L.: Surface characteristics of PLA and PLGA films. Applied Surface Science, 253, 2758-2764 (2006). https://doi.org/10.1016/j.apsusc.2006.05.047

[37] Xiu H., Qi X., Bai H., Zhang Q., Fu Q.: Simultaneously improving toughness and UV-resistance of polylactide/ titanium dioxide nanocomposites by adding poly(ether) urethane. Polymer Degradation and Stability, 143, 136144 (2017). https://doi.org/10.1016/j.polymdegradstab.2017.07.002

[38] Kopinke F-D., Remmler M., Mackenzie K., Möder M., Wachsen O.: Thermal decomposition of biodegradable polyesters - II. Poly(lactic acid). Polymer Degradation and Stability, 53, 329-342 (1996).

https://doi.org/10.1016/0141-3910(96)00102-4 